\title{
Influência do pH de coagulação e da dose de sulfato de alumínio na remoção de oocistos de Cryptosporidium por filtração direta descendente
}

\section{The influence of coagulation $\mathrm{pH}$ and aluminum sulphate dose in removal of Cryptosporidium 0ocysts by down flow direct filtration}

\author{
Neusa Margarete Gomes Fernandes \\ Engenheira Civil. Mestre em Tecnologia Ambiental e Recursos Hídricos pela Universidade de Brasília (UnB). Professora do Instituto Federal do Pará (IFPA), \\ campus Tucuruí

\section{Yovanka Perez Ginoris} \\ Engenheira Química. Doutora em Tecnologia de Processos Químicos e Bioquímicos pela Universidade Federal do Rio de Janeiro (UFRJ). Professora Adjunta da UnB

\section{Rosely Harumi Tango Rios} \\ Bióloga. Especialista em Saneamento Ambiental pelo Centro Federal de Educação Tecnológica de Minas Gerais (CEFET-MG). Professora do Instituto Federal \\ de Educação, Ciência e Tecnologia de Brasília (IFB)

\section{Cristina Célia Silveira Brandão} \\ Engenheira Química. Doutora em Engenharia Ambiental pelo Imperial College of Science, Technology and Medicine. Professora Adjunta da UnB
}

\section{Resumo}

No presente trabalho, realizado em escala piloto, foi avaliada a influência do pH de coagulação e a da dose de sulfato de alumínio na morfologia dos flocos formados durante o processo de coagulação bem como na remoção de oocistos de Cryptosporidium por filtração direta descendente. As condições de coagulação testadas incluíram a dose ótima e superdose de coagulante em duas faixas distintas de pH. Os resultados mostraram que a eficiência de remoção dos oocistos de Cryptosporidium variou de 1,4 a 3,2 log durante a operação estável do filtro. Os experimentos realizados em valores de pH de coagulação mais baixo, em torno de 5, promoveram as melhores eficiências de remoção de oocistos de Cryptosporidium. A análise morfológica dos flocos mostrou uma tendência à formação de flocos mais porosos e irregulares ao se adotar superdosagem de coagulante.

Palavra-chave: Cryptosporidium; coagulação, filtração direta descendente; morfologia dos flocos.

\section{Abstract}

This study, carried out in pilot scale, investigates the influence of coagulation $\mathrm{pH}$ and aluminum sulphate dosage on the morphology of flocs formed during coagulation and in the removal of Cryptosporidium oocysts by down flow direct filtration. Evaluated coagulation conditions included optimal and over dosages of coagulant in two distinct pH ranges. The results showed that the removal efficiency of Cryptosporidium oocysts ranged from 1.4 to 3.2 log during regular operation of the filter. Experiments carried out with lower coagulation pH values, around 5, presented the best removal efficiencies of Cryptosporidium oocysts. The morphologic analysis of flocs showed a trend to the formation of more porous and irregular flocs with the use of over dosages of coagulant.

Keywords: Cryptosporidium; coagulation; down flow direct filtration; morphology the flocs. 


\section{Introdução}

Os ecossistemas aquáticos vêm sofrendo alterações ao longo do tempo em função, principalmente, da ação antropogênica, que tem levado à degradação da qualidade ambiental. Tais condições podem favorecer a ocorrência e incidência de doenças relacionadas à água, como a criptosporidiose e a giardiose, causadas, respectivamente, pelos protozoários Cryptosporidium e Giardia. A presença crescente de novas substâncias tóxicas e organismos patogênicos na água para consumo humano em concentrações inadequadas introduz novos perigos que as barreiras dos sistemas tradicionais de tratamento de água nem sempre conseguem eliminar.

A criptosporidiose é uma doença gastrointestinal, que pode ser extremamente grave em indivíduos imunodeprimidos. O Cryptosporidium parvum é a espécie predominantemente responsável pela doença em humanos e mamíferos domésticos e apresenta oocistos medindo de 4 a $6 \mu \mathrm{m}$ de diâmetro. A membrana espessa dos oocistos desse protozoário é extremamente resistente à ação do cloro, desinfetante comumente usado no tratamento de água, particularmente no Brasil.

A infecção causada pelo Cryptosporidium parvum ocorre no mundo todo em populações urbanas e rurais, e os surtos de veiculação hídrica têm sido associados ao consumo de água potável contaminada e ao contato com águas recreacionais contaminadas (CRAUN et al, 1998).

Vários estudos relatam a ocorrência de oocistos de Cryptosporidium em água tratada, submetida a tratamentos distintos, em diferentes locais do mundo (LECHEVALLIER; NORTON, 1995; STATES et al, 1997; HELLER et al, 2004). A presença de oocistos de Cryptosporidium em água tratada ressalta a necessidade do desenvolvimento de técnicas de tratamento, ou aperfeiçoamento das existentes, do controle rigoroso dos processos de tratamento de água e do constante monitoramento dos mananciais de abastecimento.

Dentre as várias técnicas de tratamento de água, a filtração direta é uma das que apresenta menos barreiras de proteção, pelo fato de os filtros serem as únicas unidades responsáveis pela retenção do material em suspensão presente na água. Isso reforça a importância que deve ser dada ao projeto e operação dessa unidade do tratamento, bem como aos processos que antecedem à filtração, tais como a coagulação.

O fato de os oocistos de Cryptosporidium não serem partículas inorgânicas, mas sim partículas vivas com características próprias, tem sido alvo de várias pesquisas com o objetivo de verificar o seu comportamento e a influência de tais singularidades no processo de remoção. Entretanto, de acordo com Emelko, Huck e Coffey (2005), os oocistos de Cryptosporidium, comportam-se de forma similar às partículas inorgânicas e, portanto, a sua remoção por filtração envolve os mecanismos de transporte, aderência e desprendimento; além disso, as condições de pré-tratamento (coagulação) e as de filtração (taxa de filtração, amadurecimento, traspasse, meio filtrante, lavagem dos filtros) também influenciam a sua remoção.

Em razão da importância do pré-tratamento químico no desempenho das unidades de filtração e da dificuldade de inativação dos oocistos de Cryptosporidium em processos de desinfecção, torna-se fundamental estabelecer e definir as condições de coagulação que irão promover melhores eficiências de remoção físico-química desses micro-organismos. Visando contribuir para este tema, o presente trabalho avaliou a influência do pH de coagulação e dose de sulfato de alumínio na morfologia dos flocos formados após a etapa coagulação e na remoção de oocistos de Cryptosporidium por filtração direta descendente, em meio filtrante de camada dupla (antracito e areia).

\section{Metodologia}

Os experimentos foram realizados no Laboratório de Análises de Água do Departamento de Engenharia Civil e Ambiental da Universidade de Brasília e constaram de uma etapa em escala de bancada, na qual foram construídos diagramas de coagulação, e outra em escala piloto, para avaliação da remoção de oocistos de Cryptosporidium pela filtração direta descendente com meio filtrante de camada dupla (antracito sobre areia). A água utilizada no estudo era proveniente do córrego do Torto, Brasília (DF), e a suspensão de oocistos de Cryptosporidium parvum foi fornecida pela Faculdade de Medicina do Triângulo Mineiro, Uberaba, Minas Gerais.

$\mathrm{Na}$ etapa de escala de bancada foram construídos dois diagramas de coagulação para água do córrego do Torto - um referente ao período de estiagem e outro ao período das chuvas. Os diagramas de coagulação foram construídos a partir de ensaios de testes de jarros adaptados para filtração direta, segundo metodologia proposta por Di Bernardo (2003). Utilizou-se sulfato de alumínio como coagulante (0 a $\left.60 \mathrm{mg} \mathrm{Al}\left(\mathrm{SO}_{4}\right)_{3} \cdot \mathrm{L}^{-1}\right)$ e valores de $\mathrm{pH}$ de coagulação entre 5 e 7,5. As regiões de coagulação otimizadas foram selecionadas tendo como critério de qualidade a produção de água filtrada no filtro de laboratório de areia (FLA) com turbidez $\leq 0,5 \mathrm{UT}$, valor recomendado pela portaria MS 518/2004 (BRASIL, 2004) para água efluente de filtros rápidos.

A configuração da instalação piloto montada para realização dos experimentos é mostrada esquematicamente na Figura 1.

O filtro foi operado com taxa de filtração constante de 210 $\mathrm{m}^{3} \cdot\left(\mathrm{m}^{2} . \mathrm{d}\right)^{-1}$ e carga hidráulica constante. O meio filtrante de camada dupla era composto por $55 \mathrm{~cm}$ de antracito (diâmetro efetivo de 0,92 mm e coeficiente de desuniformidade de 1,52) e $40 \mathrm{~cm}$ de areia (diâmetro efetivo de 0,55 mm e coeficiente de desuniformidade de 1,6). Tais características granulométricas foram estabelecidas a partir de recomendações da literatura (Arboleda; Valência, 1992; Di Bernardo; Dantas, 2005; ABNT, 1992), do tamanho dos oocistos de Cryptosporidium (4 a $6 \mu \mathrm{m}$ ) a serem removidos e também da relação 
entre os tamanhos do menor e do maior grão dos dois materiais filtrantes, visando minimizar a mistura das camadas filtrantes durante o processo de lavagem do filtro.

As diferentes condições de coagulação testadas nos experimentos de filtração foram definidas com base no diagrama de coagulação construído previamente e confirmadas por meio de teste de jarros que eram realizados antes do início de cada experimento. Após a definição da dose de coagulante a ser usada no experimento, o pH da água bruta era corrigido, de modo que o pH de coagulação desejado fosse atendido. Em seguida, a água era inoculada com uma suspensão de oocistos de Cryptosporidium de forma a se obter uma densidade da ordem de $10^{2}$ a $10^{3}$ oocistos. $L^{-1}$ na água de estudo.

Durante o experimento de filtração, eram monitorados a perda de carga no meio filtrante, por meio de leituras nos piezômetros, a vazão e o nível da lâmina d'água. Também eram realizadas análises de turbidez, pH, alcalinidade, clorofila-a, residual de alumínio, coliformes totais, Escherichia coli e oocistos de Cryptosporidium, utilizando-se, respectivamente, os métodos nefelométrico, potenciométrico, titulométrico $\left(\mathrm{H}_{2} \mathrm{SO}_{4}-0,02 \mathrm{M}\right)$, extração em clorofórmio-metanol (2:1) com determinação da absorbância em $\lambda=665$ e 750 nm, Hach 8326 - ECR, substrato Cromogênico MUG ONPG e o método 1623 da USEPA.

Os parâmetros de $\mathrm{pH}$, turbidez e perda de carga foram medidos ao longo do experimento de filtração; entretanto, a alcalinidade, clorofila-a, residual de alumínio, coliformes totais, E. coli e oocistos de Cryptosporidium foram determinados em amostras da água bruta, da água filtrada no início do experimento de filtração (AF1), ou seja, no período em que ocorre o amadurecimento, e da água filtrada no período estável de operação do filtro (AF2). Foram realizados experimentos de filtração nas condições de coagulação indicadas na Tabela 1.

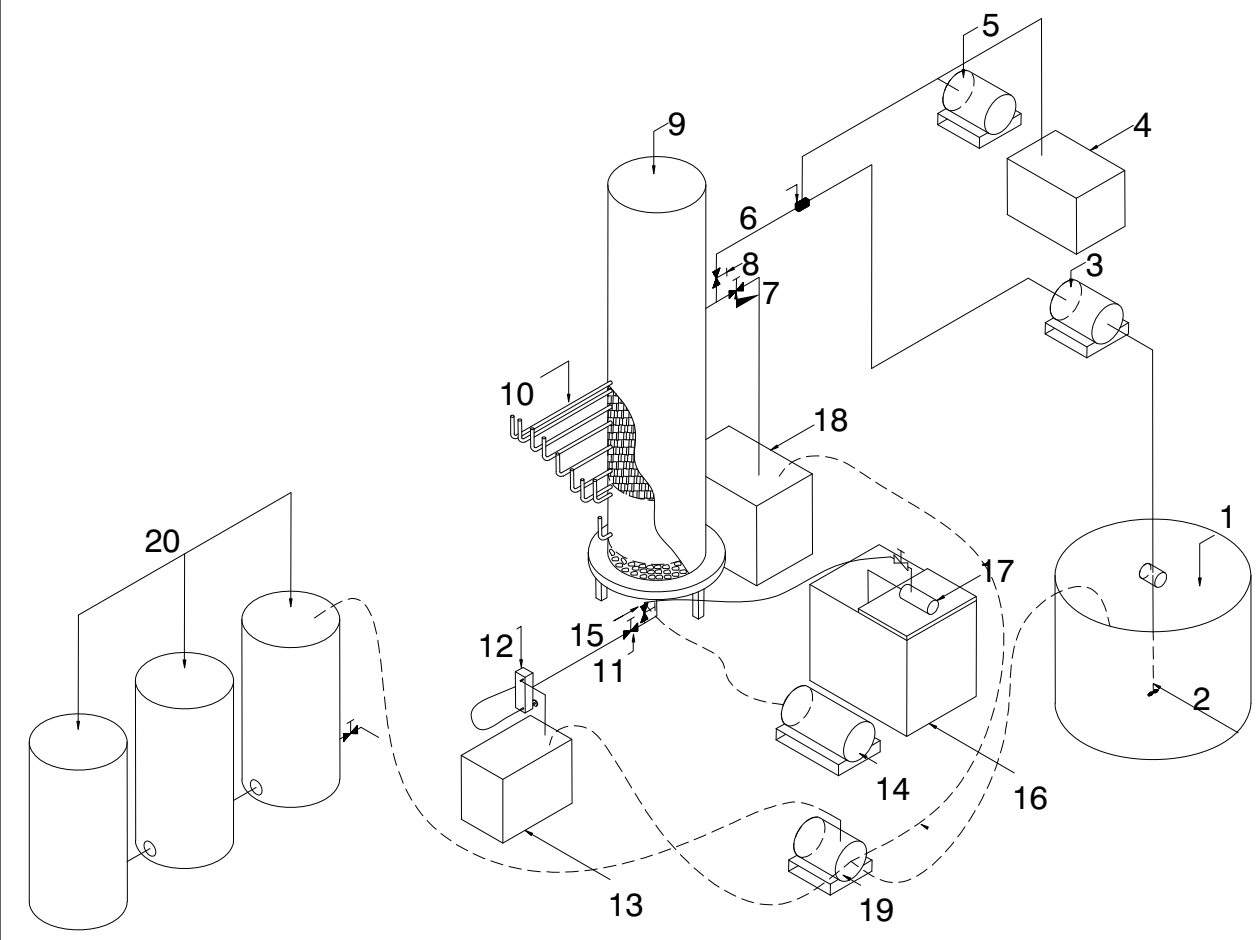

1 - reservatório de água bruta

2 - misturador mecânico

3 - bomba

4 - reservatório de coagulante

5 - bomba dosadora

6 - dispositivo de mistura rápida

7 - registro de água de lavagem

8 - registro de água coagulada

9 - coluna de filtração em acrílico

10 - piezômetros

11 - registro de água filtrada

12 - rotâmetro

13 - reservatório de água filtrada

14 - compressor de ar

15 - registro de água de lavagem e de ar

16 - reservatório de água destilada

17 - bomba

18 - reservatório de água de lavagem

19 - bomba

20 - reservatórios de descarte e desinfecção da água de lavagem

Linha contínua: tubulação de tratamento; linha tracejada: tubulação de lavagem.

Figura 1 - Esquema da instalação piloto de filtração direta descendente (sem escala).

Tabela 1 - Condições de coagulação dos experimentos de filtração

\begin{tabular}{|c|c|c|c|}
\hline \multicolumn{2}{|c|}{ Dose ótima de coagulante } & \multicolumn{2}{|c|}{ Superdose de coagulante } \\
\hline $\begin{array}{l}6 \text { a } 9 \text { mg Al2(SO4)3.L-1 } \\
\mathrm{pH}-6,8 \text { a } 6,9\end{array}$ & $\begin{array}{c}3 \text { a } 4 \text { mg Al2(SO4)3.L-1 } \\
\text { pH - 5,0 a } 5,5\end{array}$ & $\begin{array}{c}25 \mathrm{mg} \mathrm{Al2}(\mathrm{SO} 4) 3 . \mathrm{L}-1 \\
\mathrm{pH}-6,3 \text { a } 6,7\end{array}$ & $\begin{array}{c}25 \text { a } 60 \text { mg Al2(SO4)3.L-1 } \\
\text { pH }-5,0 \text { a } 5,5\end{array}$ \\
\hline Experimentos & Experimentos & Experimentos & Experimentos \\
\hline $1,2,5$ e 7 & 9,12 e 14 & $3,4,6$ e 8 & 10,11 e 13 \\
\hline
\end{tabular}


Para minimizar os efeitos da lavagem e da água remanescente no interior dos filtros sobre a qualidade da amostra de água filtrada AF1 e permitir avaliação do efeito das condições de coagulação sobre a eficiência de remoção durante o início da filtração (amadurecimento), cuidados especiais foram tomados. A lavagem do filtro era realizada com água destilada e com duração superior à usual (20 minutos) para maximizar a remoção das impurezas retidas no experimento; a realização da coleta da amostra AF1 era realizada somente após a substituição da água remanescente no filtro. Para calcular o tempo de substituição da água remanescente, experimento com traçador salino foi previamente realizado.

O termo "dose ótima" foi adotado para as condições de coagulação definidas pela menor dose de coagulante na faixa de $\mathrm{pH}$ estabelecida e que promovia a melhor remoção de turbidez (< 0,5 UT). O termo "superdose" foi adotado para fazer referência às condições de coagulação que também caíam na região otimizada de remoção de turbidez $(<0,5$ UT) no diagrama, porém com doses bem mais elevadas de coagulante.

Para verificar a morfologia dos flocos formados após processo de coagulação, foram coletadas, no início do experimento de filtração (AF1) e no período estável de operação do filtro (AF2), amostras de água coagulada. Essas amostras eram coletadas na lâmina de água coagulada acumulada sobre o meio filtrante, com auxílio de um amostrador apropriado descrito em detalhes por Fernandes (2007). Apesar de a filtração direta avaliada não contemplar etapa de floculação antes da filtração, devido ao tempo de detenção da água coagulada sobre a o meio filtrante, era visível a formação de agregados antes da água atingir a camada de antracito, caracterizando a formação de flocos mesmo sem etapa de floculação.

Para aquisição das imagens dos flocos formados, uma aliquota de $1 \mathrm{~mL}$ era cuidadosamente retirada do amostrador e depositada em lâmina Sedwick-Rafter. Para cada amostra analisada, um total de 80 imagens era capturado. O sistema de visualização e aquisição das imagens constava de um microscópio óptico Leica (Leica Microsytems, USA) acoplado a uma câmera de vídeo Leica. A aquisição das imagens, utilizando-se o software comercial Leica, foi realizada com 256 níveis de cinza e aumento total de $100 \mathrm{X}$.

Tabela 2 - Características da água bruta da barragem de nível do córrego do Torto (Brasília, DF) no período de realização dos experimentos de filtração (novembro/2006 a abril/2007)

\begin{tabular}{|lc|}
\hline Parâmetro & Faixa de valores \\
\hline Turbidez (UT) & $3,8-24,8$ \\
\hline $\mathrm{pH}$ & $6,1-6,7$ \\
\hline Alcalinidade (mg.L-1 CaCO3) & $3-6$ \\
\hline Clorofila-a ( $\mu \mathrm{g} \cdot \mathrm{L}-1)$ & $0,92-5,41$ \\
\hline Coliformes totais (NMP/100 mL) & $3,8 \times 10^{2}-6,1 \times 10^{3}$ \\
\hline Escherichia coli (NMP/100 mL) & $0,5 \times 10^{1}-7,1 \times 10^{2}$ \\
\hline
\end{tabular}

As imagens digitais dos flocos, salvas em formato TIFF, foram tratadas empregando-se o software Qwin Pro versão 3.2.0 (Leica Microsystems Image Solution, 2003), para determinar vários parâmetros da geometria euclidiana, incluindo área projetada, porosidade bidimensional (2D- $\varepsilon$ ), circularidade, fator de forma, convexidade e diâmetro equivalente dos flocos. $\mathrm{O}$ tratamento e análise das imagens foram realizados mediante o procedimento semiautomático previamente desenvolvido por Ginoris (2006).

\section{Resultados e discussão}

\section{Qualidade da água bruta}

A caracterização da água bruta do córrego do Torto, apresentada na Tabela 2, demonstra a variação típica da qualidade da água, considerando-se o período chuvoso (novembro a fevereiro) e a transição (março e abril) para o período de seca na região. Os baixos valores de alcalinidade verificados comprovam uma característica que vem sendo observada nas águas do Distrito Federal e são comparáveis a valores obtidos em outros trabalhos.

\section{Turbidez e oocistos de Cryptosporidium}

A turbidez das amostras de água filtrada no período inicial do experimento (AF1) manteve-se, na maioria dos experimentos, abaixo de 0,50 UT, enquanto os valores médios ao longo da duração dos experimentos de filtração foram inferiores a 0,15 UT, exceto nos experimentos realizados em valor de $\mathrm{pH}$ mais baixo $(5,0$ a 5,5$)$ e dose de coagulante superior à dose ótima (superdose), conforme mostra Tabela 3.

As Figuras 2 e 3 mostram que as condições de coagulação (pH e dose de coagulante) e, por consequência, os mecanismos de coagulação predominantes promoveram variações entre as remoções de turbidez e de oocistos de Cryptosporidium, principalmente no início da filtração (período de amadurecimento). No período estável de operação do filtro, as remoções de turbidez e de oocistos (Figura 3) apresentaram menor oscilação em relação ao observado no período de amadurecimento (Figura 2).

Dugan et al (2001) avaliaram a remoção de oocistos de Cryptosporidium por meio de tratamento convencional em condições de subdose de coagulante, dose ótima e coagulação melhorada. Os autores observaram que a remoção de turbidez foi sempre inferior à remoção de oocistos, sendo a diferença bem mais evidente em condições ótimas e de coagulação melhorada, concluindo que o parâmetro turbidez é um indicador conservador da remoção de oocistos. De modo geral, no presente trabalho, no período de operação estável do filtro (Figura 3), também foi observado que a remoção de turbidez foi menor que a remoção de oocistos de Cryptosporidium, particularmente quando se adotou valor de $\mathrm{pH}$ de coagulação mais baixo e dose elevada, que se 
aproxima de uma condição de coagulação melhorada. Entretanto, essa observação deve ser interpretada no contexto dos experimentos realizados, em que a densidade de oocistos de Cryptosporidium na água de estudo era elevada $\left(10^{2}\right.$ a $10^{3}$ oocistos. $\left.L^{-1}\right)$ e a turbidez, comparativamente baixa.
Os dados mostrados nas Figuras 2 e 3 sugerem, ainda, que a condição de coagulação (pH e dose de sulfato de alumínio) tende a influenciar mais a eficiência de remoção de turbidez do que a de oocistos de Cryptosporidium, sendo o exemplo mais nítido a condição de superdosagem de coagulante em valores de pH de coagulação de 5,0 a 5,5.

Tabela 3 - Turbidez da água filtrada nas condições de dose ótima e superdose

\begin{tabular}{|c|c|c|c|c|c|c|c|}
\hline \multirow{2}{*}{$\begin{array}{l}\text { Experimentos }(n)^{\star} \\
\text { (Condições de dose ótima) }\end{array}$} & 1 & 2 & 5 & 7 & 9 & 12 & 14 \\
\hline & \multicolumn{4}{|c|}{ pH de coagulação - 6,8 a 6,9 } & \multicolumn{3}{|c|}{ pH de coagulação - 5,0 a 5,5 } \\
\hline Turbidez - AF1 (UT)** & 0,15 & 0,14 & 0,14 & 0,17 & 0,18 & 0,43 & 0,13 \\
\hline Turbidez Média - (UT) & 0,11 & 0,12 & 0,12 & 0,12 & 0,13 & 0,13 & 0,09 \\
\hline \multirow{2}{*}{$\begin{array}{l}\text { Experimentos }(n)^{*} \\
\text { (Condições de superdose) }\end{array}$} & 3 & 4 & 6 & 8 & 10 & 11 & 13 \\
\hline & \multicolumn{4}{|c|}{ pH de coagulação - 6,3 a 6,7 } & \multicolumn{3}{|c|}{ pH de coagulação - 5,0 a 5,5} \\
\hline Turbidez - AF1 (UT)** & 0,14 & 0,14 & 0,13 & 0,11 & 2,09 & 1,38 & 0,74 \\
\hline Turbidez média (UT) & 0,10 & 0,10 & 0,11 & 0,10 & 1,25 & 0,61 & 0,31 \\
\hline
\end{tabular}

*A numeração dos experimentos reflete a ordem cronológica de realização e os experimentos estão agrupados segundo as condições de coagulação; **AF1: água filtrada no período inicial do experimento de filtração (amadurecimento).

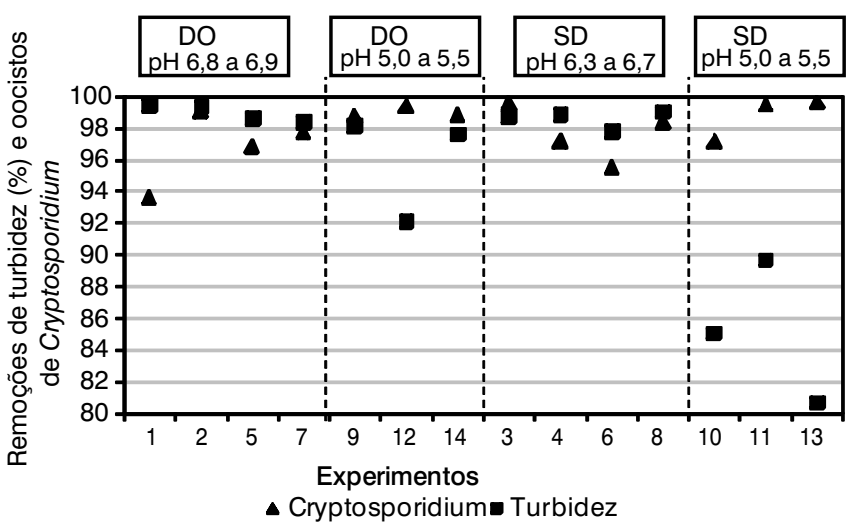

DO: dose ótima de coagulante; SD: superdose de coagulante

Figura 2 - Remoção de turbidez e de oocistos de Cryptosporidium nas amostras coletadas no período de amadurecimento (AF1).

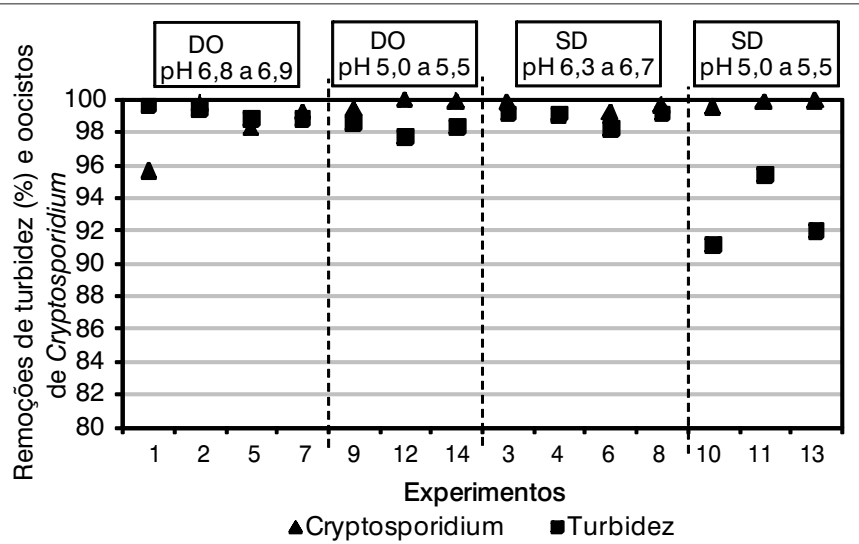

DO: dose ótima de coagulante; SD: superdose de coagulante

Figura 3 - Remoções de turbidez e de oocistos de Cryptosporidium nas amostras coletadas no período estável de operação do filtro (AF2). 
A turbidez é um parâmetro operacional importante, que reflete a eficiência dos processos de separação sólido-líquido (sedimentação e filtração). Nesse sentido, menor valor de turbidez da água filtrada para uma dada qualidade de água bruta indica maior efetividade das barreiras do tratamento e, portanto, maior segurança da água a ser distribuída para o consumo. Entretanto, diferentes pesquisas (States et al, 1997; Aboytes et al, 2004; Fernandes, 2007) têm mostrado que mesmo produzindo-se água filtrada com valores baixos de turbidez (menores que 0,2 UT), pode ocorrer passagem de oocistos de Cryptosporidium no tratamento de água em função da densidade desses organismos na água bruta.

A fase de amadurecimento é considerada um período crítico quanto à passagem de partículas pelo meio filtrante, em decorrência do residual da água de lavagem e também pela dificuldade de aderência das partículas aos grãos coletores, fatores que podem favorecer também a passagem de micro-organismos. Os resultados apresentados na Figura 4 mostram essa tendência. Nas diferentes condições de coagulação, o filtro de camada dupla foi capaz de promover eficiências de remoção dos oocistos de Cryptosporidium na faixa de 1,2 a 2,4 log no início do experimento (AF1) e de 1,4 a 3,2 log no período estável de operação (AF2).
Praticamente todos os experimentos de filtração - com exceção daqueles realizados em condições de superdosagem de coagulante e valor de pH de coagulação baixo - produziram água filtrada com valores de turbidez inferiores a 0,2 UT, atendendo, portanto, aos critérios considerados como correspondentes à remoção efetiva de oocistos de Cryptosporidium por filtração direta (2,5 log) (USEPA, 2006). Entretanto, provavelmente em função da qualidade da água de estudo, a remoção de oocistos de Cryptosporidium no período estável de operação (AF2) atingiu valores superiores a 2,5 log apenas em cerca de metade dos experimentos.

\section{Morfologia dos flocos - Análise de imagem}

Os parâmetros morfológicos, obtidos após a análise digital das imagens, mostraram que os flocos formados nas distintas condições de coagulação estudadas exibiram diferenças no aspecto físico. A Figura 5 ilustra as imagens digitais representativas dos flocos obtidos nas quatro condições de coagulação estudadas.

Os flocos formados em condições de dosagem ótima, de modo geral, apresentaram valores de convexidade $(0,71$ a 0,84$)$ e circularidade

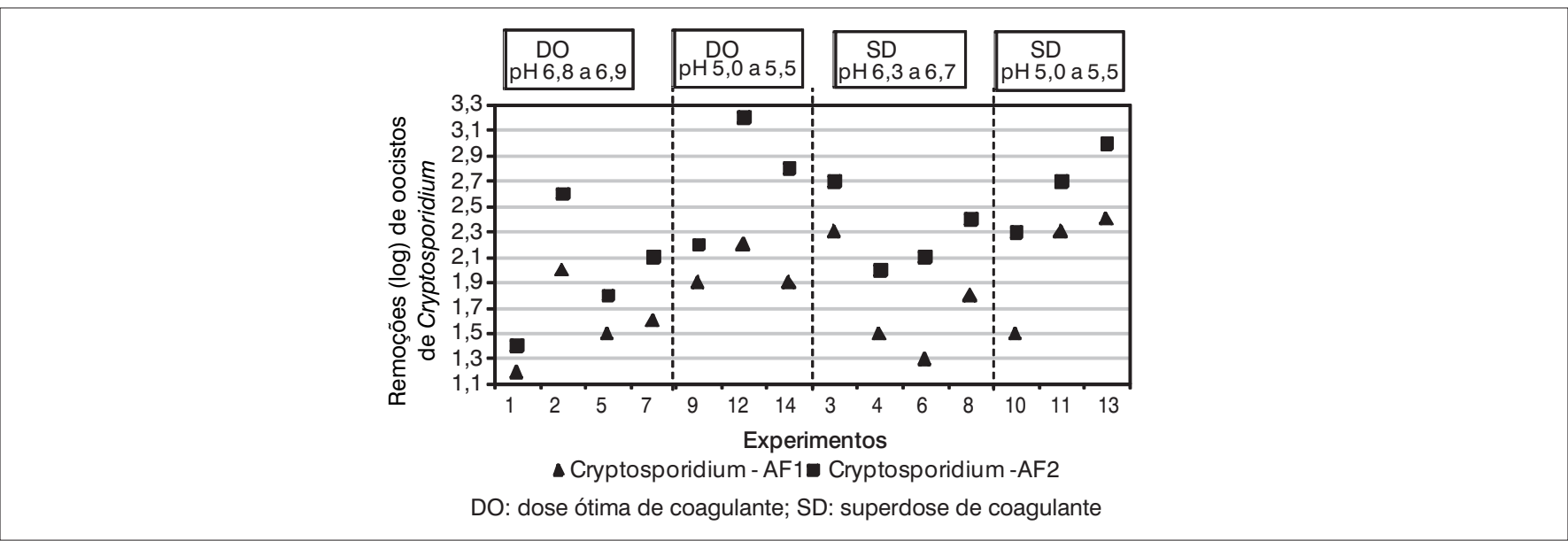

Figura 4 - Remoções de 0ocistos de Cryptosporidium nas amostras coletadas no período de amadurecimento de água (AF1) e no período estável de operação do filtro (AF2).

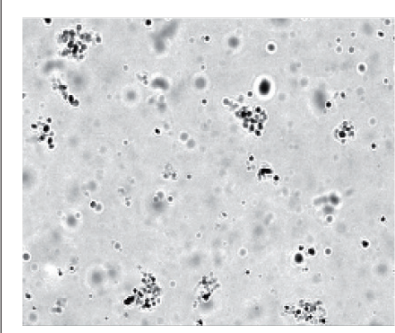

$\mathrm{DO}$ e $\mathrm{pH}(6,8-6,9)$

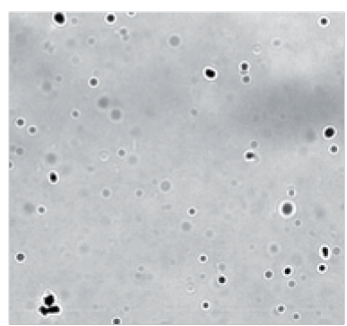

$\mathrm{DO}$ e $\mathrm{pH}(5,0-5,5)$

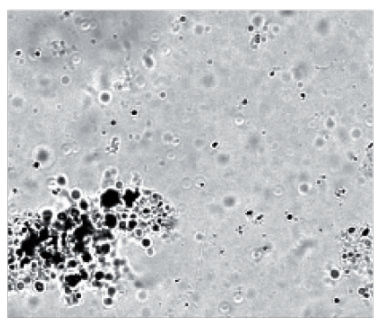

$\mathrm{SD}$ e $\mathrm{pH}(6,3-6,7)$

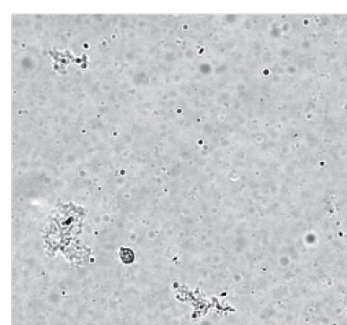

$\mathrm{SD}$ e $\mathrm{pH}(5,0-5,5)$

(DO: dose ótima de coagulante; SD: superdose de coagulante).

Figura 5 - Imagens digitais referentes aos flocos formados no processo de coagulação, obtidas por meio da técnica microscópica de campo claro com aumento $100 \mathrm{X}$ 
$(2,3$ a 4,0) mais próximos da unidade quando comparados com os valores obtidos para os mesmos parâmetros em condições de superdose de coagulante ( 0,65 a 0,76 e 3,1 a 5,0, respectivamente). Essa diferença sugere que os flocos formados sob condição de dosagem ótima tendem a apresentar estrutura mais regular do que os flocos originários da superdosagem, particularmente em condições de baixo valor de $\mathrm{pH}$, em que o mecanismo de adsorção e neutralização de cargas tende a predominar. Nessas condições a convexidade e a circularidade dos flocos apresentam valores, respectivamente, de 0,72 a 0,85 e de 2,3 a 2,7, reforçando a maior proximidade desses agregados às estruturas circulares.

Observou-se também que a porosidade bidimensional (2D-E) dos flocos em condições de dosagem ótima $(0,028$ a 0,105) foi, em geral, menor do que a porosidade dos flocos desenvolvidos em condições de superdosagem $(0,065$ a 0,168$)$, o que sugere que os flocos originários das condições de dosagem ótima eram mais compactos dos que aqueles obtidos em condições de superdosagem.

Os histogramas de distribuição de frequências de tamanho dos flocos formados no processo de coagulação, disponíveis em Fernandes (2007), mostraram que, independentemente das condições de coagulação avaliadas, de modo geral, os flocos presentes nas amostras analisadas apresentaram tamanhos na faixa de 20 a $160 \mu$ m e que a maior frequência de tamanhos correspondeu ao intervalo compreendido entre 40 e $60 \mu \mathrm{m}$.

\section{Efeitos do pH de coagulação e da dose de coagulante}

Para verificar o efeito das condições de coagulação na remoção de turbidez e de oocistos de Cryptosporidium, bem como a morfologia dos flocos, os resultados obtidos nos experimentos de filtração foram tratados estatisticamente aplicando-se o teste não paramétrico de análise de variância de Kruskal-Wallis. Os resultados referentes ao teste nas quatro condições de coagulação estudadas são mostrados na Tabela 4 , em que os valores tabelados correspondem à hipótese $\mathrm{H}(3, \mathrm{~N}=14)$.

Confirmando o discutido no item anterior, os resultados do teste de Kruskal-Wallis (Tabela 4) mostraram que as condições de coagulação influenciaram significativamente os parâmetros morfológicos dos flocos $(p<0,05)$, exceto no que se refere ao tamanho dos flocos, estimado pelo diâmetro equivalente.

Os resultados do teste indicaram também efeito significativo das condições de coagulação na remoção turbidez, tanto na fase de amadurecimento (AF1), como no período estável de operação do filtro (AF2), e também ao longo do tempo de operação do filtro, com valores de probabilidade inferiores a 0,05. Com base no valor da soma das classificações (Tabela 4), observa-se que as maiores remoções média de turbidez corresponderam a valores de $\mathrm{pH}$ mais próximos da neutralidade, independentemente da dose adotada, enquanto as menores remoções foram obtidas em condição de superdosagem e valor de $\mathrm{pH}$ baixo (piores valores de turbidez da água filtrada AF1 e AF2).

Por outro lado, o teste mostrou que as eficiências de remoção de oocistos de Cryptosporidium não foram influenciadas de modo significativo - ao nível de 95\% de confiabilidade - pela adoção de condições de coagulação distintas. Contudo, quando se analisa a remoção de oocistos no período estável de operação do filtro, verifica-se que o valor de probabilidade é bem próximo de 0,1 , indicando a possibilidade de influência das condições de coagulação na remoção de oocistos, considerado-se um limite de confiabilidade mais flexível, de 90\%. Nesse caso, observa-se que, diferentemente do verificado para remoção de turbidez, a remoção de oocistos

Tabela 4 - Influência das condições de coagulação na morfologia dos flocos, na remoção de turbidez e de oocistos de Cryptosporidium. Resultados do teste de Kruskal-Wallis

\begin{tabular}{|c|c|c|c|c|c|c|}
\hline \multirow[b]{2}{*}{ Parâmetros } & \multicolumn{4}{|c|}{ Soma das classificações } & \multirow{2}{*}{$\stackrel{H}{H}(3, N=14)$} & \multirow{2}{*}{$\begin{array}{l}\text { Probabilidade } \\
\text { (p) }\end{array}$} \\
\hline & $\begin{array}{c}\mathrm{DO} \\
\mathrm{pH}(6,8-6,9)\end{array}$ & $\begin{array}{c}\mathrm{DO} \\
\mathrm{pH}(5,0-5,5)\end{array}$ & $\begin{array}{c}\mathrm{SD} \\
\mathrm{pH}(6,3-6,7)\end{array}$ & $\begin{array}{c}\text { SD } \\
\mathrm{pH}(5,0-5,5)\end{array}$ & & \\
\hline Turbidez AF1 & 28 & 23,5 & 14,5 & 39 & 8,9 & $0,03^{*}$ \\
\hline Turbidez AF2 & 29,5 & 22 & 14,5 & 39 & 8,8 & $0,03^{*}$ \\
\hline Remoção média de Turbidez & 41 & 17 & 41 & 6 & 9,4 & $0,02^{*}$ \\
\hline Remoção de oocistos de Cryptosporidium (AF1) & 20 & 28 & 27 & 30 & 3,2 & 0,36 \\
\hline Remoção de oocistos de Cryptosporidium (AF2) & 17 & 32 & 25 & 31 & 5,9 & 0,12 \\
\hline Porosidade (2D-€) & 25,5 & 6,5 & 50 & 23 & 10,9 & $0,01^{*}$ \\
\hline Circularidade & 25 & 10 & 49 & 21 & 8,6 & $0,03^{*}$ \\
\hline Convexidade & 33 & 34 & 11 & 27 & 8,2 & $0,04^{\star}$ \\
\hline Fator de forma & 31 & 34 & 12 & 28 & 7,7 & $0,05^{\star}$ \\
\hline Diâmetro equivalente & 24 & 27 & 22 & 32 & 3,5 & 0,32 \\
\hline
\end{tabular}

*Efeitos significativos ao nível de 95 \% de confiança; DO: dosagem ótima de coagulante; SD: superdose de coagulante. 
de Cryptosporidium tende a ser maior (maior soma das classificações) em valores de $\mathrm{pH}$ mais baixo, independentemente da dose de coagulante adotada, sugerindo que os mecanismos de coagulação influenciam de formas distintas a remoção de partículas inertes e oocistos.

Assim, com o objetivo de inferir sobre os possíveis mecanismos de coagulação atuantes nas diferentes condições experimentais testadas e buscar entender as diferenças observadas com relação à influência das condições de coagulação na remoção de turbidez e de oocistos, utilizou-se o artifício de sobrepor as condições de coagulação avaliadas sobre o diagrama de coagulação de Amirtharajah e Mills (1982). Os pontos experimentais estão plotados no diagrama de coagulação ilustrado na Figura 6.

$\mathrm{Na}$ Figura 6, é possível observar que, em valores de $\mathrm{pH}$ mais próximos da neutralidade, tanto nas condições de dose ótima de coagulante (6 a $9 \mathrm{mg} \cdot \mathrm{L}^{-1}$ de $\mathrm{Al}_{2}\left(\mathrm{SO}_{4}\right)_{3}$ ou 10,5 a $16 \mathrm{mg} \cdot \mathrm{L}^{-1}$ de $\left.\mathrm{Al}_{2}\left(\mathrm{SO}_{4}\right)_{3} \cdot 14,3 \mathrm{H}_{2} \mathrm{O}\right)$, como na condição de superdose ( $25 \mathrm{mg} / \mathrm{L}$ de sulfato de alumínio anidro ou $44 \mathrm{mg} \cdot \mathrm{L}^{-1}$ de $\left.\mathrm{Al}_{2}\left(\mathrm{SO}_{4}\right)_{3} \cdot 14,3 \mathrm{H}_{2} \mathrm{O}\right)$, os mecanismos de coagulação atuantes incluem a varredura. Por outro lado, nas condições de pH de coagulação entre 5,0 e 5,5 e dosagens ótimas de 3 a $4 \mathrm{mg} / \mathrm{L}$ de sulfato de alumínio anidro ( 5 a $7 \mathrm{mg} \cdot \mathrm{L}^{-1}$ de $\left.\mathrm{Al}_{2}\left(\mathrm{SO}_{4}\right)_{3} \cdot 14,3 \mathrm{H}_{2} \mathrm{O}\right)$, a sobreposição dos dados no diagrama de Amirtharajah e Mills (1982) (Figura 6) sugere que, provavelmente, a adsorção e neutralização de cargas é o mecanismo predominante.

Devido aos oocistos de Cryptosporidium apresentarem carga superficial negativa, ou seja, potencial zeta negativo (Drozd; Schwartzbrod, 1996; Ongerth; Pecoraro, 1996) as espécies hidrolisadas solúveis de alumínio podem ser adsorvidas formando um floco desestabilizado. Entretanto, segundo Marklund et al. e Cotton e Wilkinson (1980) (apud Bustamante et al, 2001), as espécies de alumínio não são apenas adsorvidas na superfície dos oocistos, mas também interagem quimicamente com os grupos carboxilados e fosfatados aí presentes. De acordo com Bustamante et al. (2001), esses locais produziriam pontos de ancoramento onde as espécies hidrolisadas seriam especificamente aderidas e os flocos, construídos em torno deles.

Assim, a interação química entre o alumínio e substâncias específicas da parede dos oocistos podem ter contribuído para maiores remoções dos oocistos de Cryptosporidium, quando comparado com a remoção de turbidez (Figuras 2 e 3 e Tabela 4), na condição de valores de pH de coagulação mais baixo e dose ótima, uma vez que essas interações químicas podem não acontecer com as partículas inorgânicas.

Analisando-se as condições de superdose (25 a 60 mg. $\mathrm{L}^{-1}$ de sulfato de alumínio anidro ou 44 a $105 \mathrm{mg} \cdot \mathrm{L}^{-1}$ de $\left.\mathrm{Al}_{2}\left(\mathrm{SO}_{4}\right)_{3} \cdot 14,3 \mathrm{H}_{2} \mathrm{O}\right)$

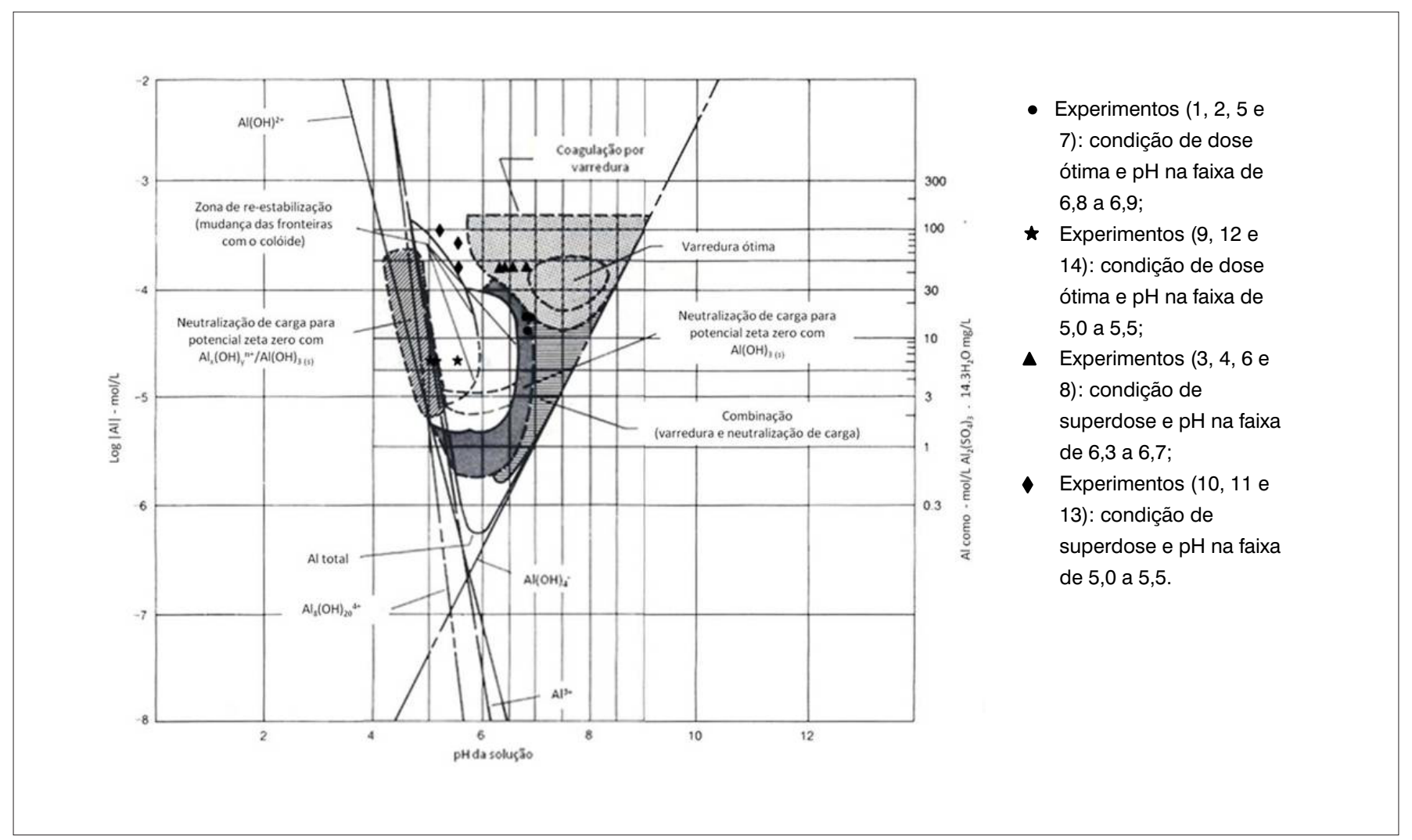

Figura 6 - Sobreposição das condições de coagulação utilizadas no presente trabalho (pares de valores de pH e dose de sulfato de alumínio) no diagrama de coagulação de Amirtharajah e Mills (1982). 
e pH de coagulação entre 5,0 e 5,5, observa-se, na Figura 6, que os pontos experimentais incidem em região com mecanismo não identificado no diagrama, próximos a zonas de desestabilização, mas em região em que, de acordo com o diagrama de solubilidade do alumínio, ocorre a formação do hidróxido de alumínio. Os resultados obtidos nos experimentos de filtração nessas condições de coagulação (Figuras 2 e 3 e Tabela 4) mostram eficiências de remoção de turbidez menores e elevadas eficiências de remoção de oocistos de Cryptosporidium

Segundo Amirtharajah e Mills (1982), a delimitação da região de reestabilização no diagrama de coagulação com sulfato de alumínio varia em função da área superficial dos coloides, especialmente o limite inferior. A delimitação superior da região de reestabilização (nova condição de desestabilização), por sua vez, tem sido creditada à presença de íons $\mathrm{SO}_{4}^{2-}$ e ao aprisionamento dos coloides reestabilizados em complexos de sulfato ou de hidróxido de alumínio precipitado. É possível que esse mecanismo esteja contribuindo para a remoção das partículas em geral. Entretanto, a diferença de comportamento entre a remoção de turbidez e de oocistos nos experimentos 10, 11 e 13 aponta para a hipótese da existência de outros fatores, além das espécies de alumínio formadas, que influenciam na remoção dos oocistos de Cryptosporidium e que também são dependentes do valor do $\mathrm{pH}$.

Segundo Drozd e Schwartzbrod (1996), a hidrofobicidade e o potencial zeta são parâmetros relacionados com as características químicas e a estrutura dos oocistos de Cryptosporidium, tendo influência nos mecanismos complexos da adesão desses micro-organismos quando associados às partículas suspensas. Esses autores observaram que o potencial hidrofóbico da superfície dos oocistos aumenta quando o $\mathrm{pH}$ alcança valores extremos e decresce ao mínimo em valor de $\mathrm{pH}$ 7. Para as cargas superficiais (potencial zeta) dos oocistos, os mesmos autores relatam acréscimo no valor do potencial zeta com a redução do valor do $\mathrm{pH}$, partindo de $-35 \mathrm{mV}$ para $\mathrm{pH}$ alcalino e alcançando 0 $\mathrm{mV}$ para pH ácido $(2,5)$. De acordo com o que foi exposto, sugere-se que o aumento da hidrofobicidade dos oocistos de Cryptosporidium e o potencial zeta mais próximo do ponto isoelétrico nas condições de $\mathrm{pH}$ mais baixo favorecem tanto os processos de coagulação dos oocistos de Cryptosporidium quanto os processos de aderência ao meio filtrante, explicando a elevada remoção de oocisto observadas em valor de
$\mathrm{pH}$ próximo de 5, independentemente da dose de coagulante adotada (ótima ou superdose).

\section{Conclusões}

Os experimentos realizados em valores de $\mathrm{pH}$ de coagulação mais baixo, em torno de 5, promoveram as melhores eficiências de remoção de oocistos de Cryptosporidium, particularmente em relação ao período estável de operação do filtro. Na condição de dosagem ótima de coagulação, possivelmente ocorreu predominância do mecanismo de adsorção e neutralização de cargas, recomendado quando se utiliza a filtração direta.

O baixo valor do pH de coagulação pode ter influenciado a remoção dos oocistos de Cryptosporidium também por favorecer a hidrofobicidade dos oocistos e reduzir, independentemente do mecanismo de coagulação, a repulsão entre os mesmos. Esses fatores também podem ter contribuído para a boa eficiência de remoção de oocistos em condição de superdosagem.

O período de amadurecimento apresentou maior vulnerabilidade quanto à passagem de oocistos de Cryptosporidium quando comparado ao período estável de operação dos filtros. Em função da forma criteriosa de lavagem adotada nos experimentos, sugere-se que a menor eficiência de remoção de oocistos de Cryptosporidium esteja relacionada à menor eficiência dos mecanismos de aderência durante a fase inicial do experimento de filtração.

Não obstante o trabalho desenvolvido tenha permitido a reflexão sobre a importância das condições de coagulação (dose de coagulante e pH de coagulação) na remoção de oocistos de Cryptosporidium, o pequeno número de experimentos realizados e as dificuldades e observações verificadas ao longo dos mesmos limitam a extrapolação dos resultados obtidos. Ressalta-se, portanto, a necessidade de realizar novos experimentos, com número maior de repetições para cada condição de coagulação testada, especialmente em condições de baixo valor de pH, e inclusão da determinação do potencial zeta para agregar mais informações sobre os mecanismos de coagulação e possibilitar entendimento conclusivo dos fenômenos envolvidos na coagulação e filtração de oocistos de Cryptosporidium.

\section{Referências}

ASSOCIAÇÃO BRASILEIRA DE NORMAS TÉCNICAS (ABNT). NBR 12216 - Projeto de Estação de Tratamento de Água para Abastecimento Público. Rio de Janeiro: ABNT, 1992

ABOYTES, R. et al. Detection of infectious Cryptosporidium in filtered drinking water. Journal of the American Water Works Association, v. 96, n. 9, p. 88-98, 2004
AMIRTHARAJAH, A.; MILLS, K.M. Rapid-mix design for mechanism of alum coagulation. Journal of the American Water Works Association, v. 74 , n. 4 , p. $210-216,1982$

ARBOLEDA VALÊNCIA, J. Teoría y Práctica de la Purificación del Agua. Asociation Colombiana de Ingenieria Sanitaria y Ambiental. Bogotá: ACODAL, 1992 
BRASIL Ministério da Saúde. Portaria no 518, de 25 de março de 2004. Estabelece os procedimentos e responsabilidades relativos ao controle e vigilância da qualidade da água para consumo humano e seu padrão de potabilidade, e dá outras providências. Brasília: Ministério da Saúde, 2004.

BUSTAMANTE, H.A. et al. Interaction between Cryptosporidium oocysts and water treatment coagulants. Water Research, v. 35, n. 13, p. 31793189, 2001.

CRAUN, G.F. et al. Waterborne outbreaks of cryptosporidiosis. Journal of the American Water Works Association, v. 90, n. 9, p. 81-91, 1998.

DI BERNARDO, L. (Coord.). Tratamento de Água para Abastecimento por Filtração Direta. Rio de Janeiro: ABES, Rima, 2003. (Projeto Prosab).

DI BERNARDO L.; DANTAS, A.D.B. Métodos e técnicas de tratamento de água. v. 1, 2. ed. São Carlos: Rima, 2005.

DROZD, C.; SCHWARTZBROD, J. Hydrophobic and electrostatic cell surface properties of Cryptosporidium parvum. Applied and Environmental Microbiology, v. 62, n. 4, p. 1227-1232, 1996.

DUGAN, N.R. et al. Controlling Cryptosporidium oocysts using Conventional treatment. Journal of the American Water Works Association, v. 93, n. 12, p. $64-77,2001$

EMELKO, M.B.; HUCK, P. M.; COFFEY, B. M. A review of Cryptosporidium removal by granular media filtration. Journal of the American Water Works Association, v. 97, n. 12, p. 101-115, 2005.
FERNANDES, N.M.G. Influência do pH de Coagulação e Dosagem de Sulfato de Alumínio na Remoção de Oocistos de Cryptosporidium por Filtração Direta Descendente. Dissertação (Mestrado em Tecnologia Ambiental e Recursos Hídricos). Universidade de Brasília, Brasília, 2007.

GINORIS, Y.P. Aplicação de Técnicas de Análise de Imagens no Monitoramento de Sistemas de Lodo Ativado. Tese (Doutorado em Tecnologia de Processos Químicos e Bioquímicos). Universidade Federal do Rio de Janeiro, Rio de Janeiro, 2006.

HELLER, L. et al. Oocistos de Cryptosporidium e cistos de Giardia: circulação no ambiente e riscos à saúde humana. Epidemiologia e Serviços de Saúde, v. 13, n. 2, p. 79-92, 2004.

LECHEVALLIER, M.W.; NORTON, W.D. Giardia and Cryptosporidium in raw and finished water. Journal of the American Water Works Association, v. 87, n. 9, p. 54-67, 1995 .

ONGERTH J.E.; PECORARO, J.P. Electrophoretic mobility of Cryptosporidium oocysts and Giardia cysts. Journal of Environmental Engineering, v. 122, n. 3, p. 228-231, 1996.

STATES, S. et al. Protozoa in river water: sources, occurrence and treatment. Journal of the American Water Works Association, v. 89, n. 9, p. $74-82,1997$.

UNITED STATES ENVIRONMENTAL PROTECTION AGENCY (USEPA) (2006). National Primary Drinking Water Regulations: Long Term 2 Enhanced Surface Water Treatment Rule; Final Rule. 40 CFR Parts 9, 141, and 142. (2006) 